\title{
Relative impacts of two exotic brachyuran species on blue mussel populations in Long Island Sound
}

\author{
Andrew M. Lohrer*, Robert B. Whitlatch \\ Department of Marine Sciences, University of Connecticut, Groton, Connecticut 06340, USA
}

\begin{abstract}
Green crabs Carcinus maenas were introduced to North America in the early 1800s and breeding populations were subsequently established in southern New England. Green crabs became dominant predators in rocky intertidal habitats of the region and caused ecological and economic harm in the ensuing decades. During the mid-1990s, the rocky intertidal crab fauna of southern New England began to change once again. A reduction in green crab abundance was coincident with the introduction and spread of another exotic crab species, the Asian shore crab Hemigrapsus sanguineus. Less than $10 \mathrm{yr}$ after its appearance in Long Island Sound, H. sanguineus became the numerically dominant brachyuran at several rocky intertidal sites in the region (e.g. $90+\%$ of the crabs were $H$. sanguineus; densities of $H$. sanguineus often exceeded $70 \mathrm{crabs} \mathrm{m}^{-2}$ ). This study examined consequences of the invasion by $H$. sanguineus and the decline of $C$. maenas on a shared prey population in the rocky intertidal zone. Both crab species readily consumed native blue mussels (Mytilus edulis) and rates of mussel loss (per predator, per species) were quantified during a series of field experiments. While $C$. maenas consumed more mussels than $H$. sanguineus on an individual basis, the greater densities of $H$. sanguineus made it an important predator of juvenile mussels from a population standpoint. In isolation, the decline of C. maenas (a voracious alien predator) would have benefited mussel populations. However, the replacement of $C$. maenas by $H$. sanguineus has apparently had a net negative influence on intertidal blue mussel populations.
\end{abstract}

KEY WORDS: Exotic marine species $\cdot$ Hemigrapsus sanguineus $\cdot$ Carcinus maenas $\cdot$ Post-settlement predation $\cdot$ Crabs $\cdot$ Mytilus edulis

\section{INTRODUCTION}

The introduction and spread of non-indigenous species poses a significant ecological and economic threat to coastal marine communities, particularly in bays and estuaries (Carlton 1989, Carlton \& Geller 1993, Cohen \& Carlton 1998). Long Island Sound, a major estuary in northeastern North America, has been invaded by many alien species in the recent and historical past (e.g. Carlton 1989, 1993, Berman et al. 1992, Whitlatch

\footnotetext{
${ }^{*}$ Present address: Baruch Marine Field Laboratory, University of South Carolina, PO Box 1630, Georgetown, South Carolina 29442, USA. E-mail: lohrer@belle.baruch.sc.edu
}

et al. 1995). At present, several of the most common and conspicuous organisms in Long Island Sound are non-indigenous, including gastropods (Littorina littorea), decapods (Carcinus maenas, Hemigrapsus sanguineus), ascidians (Styela clava, Botrylloides violaceous, Ascidiella adspersa, Diplosoma listerianum), and macroalgae (Codium fragile). In highly invaded habitats such as this one, it is likely that exotic species populations will interact. However, experimental investigations involving 2 or more exotic species (e.g. Osman \& Whitlatch 1995a,b, Stachowicz et al. 1999) are relatively rare in the field of marine invasion ecology. Here, we describe the per capita and populationlevel effects of predation by 2 alien crab species that co-occur in Long Island Sound. 
While the European green crab Carcinus maenas has been present in Long Island Sound for almost $200 \mathrm{yr}$, the Asian shore crab Hemigrapsus sanguineus became established much more recently (<10 yr ago; Williams \& McDermott 1990, Carlton 1993, McDermott 1998a). The 2 crabs often co-occur in moderately exposed rocky intertidal habitats in eastern Long Island Sound (Lohrer \& Whitlatch 1997) and there is mounting evidence that crab-crab interactions are important in this system. Field surveys and experimental work strongly suggest that $H$. sanguineus may be displacing C. maenas from rocky intertidal habitats in southern New England by preying on young-of-the-year $C$. maenas that seek refuge amongst the cobbles and boulders (Lohrer 2000). For other resident organisms, particularly species that are commonly eaten by intertidal crabs, the displacement of C. maenas by H. sanguineus may have substantially altered existing ecological conditions. Therefore, using the present and historical effects of $C$. maenas for context, we assessed the net impact of $H$. sanguineus on the native blue mussel Mytilus edulis, an ecologically and commercially important bivalve that occupies rocky intertidal and subtidal habitats throughout southern New England.

Interactions between green crabs and blue mussels have been examined in great detail (Kitching et al. 1959, Ebling et al. 1964, Davies 1966, Leonard et al. 1999) and the feeding biology of Carcinus maenas is very well characterized (Ropes 1968, 1989, Elner \& Hughes 1978, Elner 1981, references in Grosholz \& Ruiz 1995, Lohrer \& Whitlatch 1997). In contrast, virtually nothing was known about the feeding habits of Hemigrapsus sanguineus when it arrived in North America. Recent work indicates that mytilid bivalves are prominent in the natural diet of $H$. sanguineus in both native and invaded habitats (McDermott 1998b, Lohrer et al. 2000).

Prior to the arrival of Hemigrapsus sanguineus in southern New England, Carcinus maenas was probably the dominant crustacean predator of blue mussels in rocky intertidal habitats (J. T. Carlton pers. comm., Glude 1955, Dean 1979). The situation is less clear now that $H$. sanguineus has invaded these habitats (H. sanguineus densities have probably not equilibrated and are apparently still rising; Lohrer 2000). The impact of $H$. sanguineus on intertidal mussel populations is likely size-dependent, with disproportionately strong effects on small size classes. Large mussels are probably immune to predation from all except the largest crabs because $H$. sanguineus never attains sizes $>43 \mathrm{~mm}$ carapace width (CW) (Fukui 1988, Juanes 1992, McDermott 1998b). However, the high densities of $H$. sanguineus in some intertidal locations may significantly affect the survival of small mussels. Intertidal habitats are often viewed as refuges from predation and as nursery areas for recruit and juvenile life-stages (Paine 1976, Underwood \& Denley 1984, Reise 1985, Peterson 1991). H. sanguineus, having achieved average densities of 60 to $90 \mathrm{crabs} \mathrm{m}^{-2}$ at several rocky sites in southern New England (Lohrer 2000), may be decreasing the refuge value of this habitat type by increasing the predation pressure relative to C. maenas. To test this hypothesis, several laboratory and field experiments were conducted to ascertain the relative impacts of $H$. sanguineus and $C$. maenas as predators of juvenile blue mussels.

\section{MATERIALS AND METHODS}

Site description. All of the field work described hereafter was performed in a moderately exposed, rocky intertidal habitat at Millstone Point, CT, USA $\left(41^{\circ} 18.862^{\prime} \mathrm{N}, 72^{\circ} 10.324^{\prime} \mathrm{W}\right.$; semi-diurnal tides, mean tidal range $=0.82 \mathrm{~m}$ ). At this site, an assemblage of rocks and cobbles was strewn over a sandy substratum. Coverage of stones averaged 68 to $82 \%$ and a thick macroalgal canopy was present below the midtide level (Fucus spp. $\geq 80 \%$ coverage). The width, vertical slope $\left(3^{\circ}\right.$ to $\left.11^{\circ}\right)$, and general characteristics of the intertidal zone did not differ greatly over a horizontal distance of $\sim 300 \mathrm{~m}$ (i.e. parallel to the shoreline). Millstone Point was favored over other locations because public access to the site was restricted. Furthermore, unlike many sites in southern New England, green crabs were still relatively common in the rocky intertidal zone at Millstone Point (Lohrer 2000).

Field surveys of crabs. To estimate population densities and sizes of brachyuran crabs inhabiting the site, surveys were conducted during spring low tides in June and September of 1998 and 1999 (i.e. 4 separate crab surveys). In each survey, crabs were sampled from 20 quadrats $\left(\right.$ size $=1 \mathrm{~m}^{2}$ ). However, sampling was stratified, with 5 quadrats sampled from each of 4 intertidal heights (approximately 10, 30, 60, and $80 \mathrm{~cm}$ above mean low water, MLW). After collection, each crab was identified, sexed, measured, and released again. While recruits and small juveniles (i.e. Hemigrapsus sanguineus $<8 \mathrm{~mm} \mathrm{CW}$ and Carcinus maenas $<10 \mathrm{~mm} \mathrm{CW}$ ) were abundant in September following settlement from the plankton, they were excluded from all analyses performed during this investigation.

Crabs that migrated with the tides (i.e. crabs present in the intertidal zone at Millstone Point only during high water) were not effectively sampled during low tide surveys. To address this potential problem, crab traps $(\mathrm{n}=4)$ were baited with 5 to 7 cracked blue mussels and were deployed at Millstone Point for 2 complete tidal cycles. The traps were spaced 20 to $30 \mathrm{~m}$ 
apart to cover a wide horizontal section of the shoreline. The apertures on the traps were designed to capture large crabs (up to $85 \mathrm{~mm} \mathrm{CW}$ ). This trap/bait combination attracted many large green crabs in other studies (Berger 1998, A.M.L. pers. obs.).

Field surveys of Mytilus edulis. To assess the population dynamics of $M$. edulis during the study period, surveys of blue mussels were conducted at Millstone Point in July 1998 and July 1999. In each year, small quadrats $(25 \mathrm{~cm} \times 25 \mathrm{~cm} ; \mathrm{n}=18)$ were randomly dispersed along a horizontal transect at $+40 \mathrm{~cm}$ MLW. Mussels found within the quadrats were counted and all were measured (shell lengths [SL], mm). The goal was to determine population density and population size structure of $M$. edulis at the same intertidal elevation that the caging experiments were conducted (see 'Field caging experiments').

Laboratory feeding experiments. To assess the potential influence of Hemigrapsus sanguineus on blue mussel populations, a series of feeding trials were conducted in the laboratory. Large male $H$. sanguineus (25 to $30 \mathrm{~mm} \mathrm{CW}$ ) were collected from the field and held in a flow-through seawater system for $1 \mathrm{~d}$ to standardize hunger levels. The crabs, placed in individual $11 \mathrm{con}$ tainers, were then presented with mussels 5 to $10 \mathrm{~mm}$ SL. The number of mussels varied (e.g. 1, 2, 4, 8, 16, $32,64,100,128,264)$ and several healthy, intermolt crabs were used for each of the prey density treatments $(7+$ replicates in 9 of the 10 treatments, 4 replicates for the highest density treatment). Water temperature was not controlled during the feeding trials (i.e. ambient seawater from eastern Long Island Sound flowed through experimental tanks). It varied between $14^{\circ}$ and $19^{\circ} \mathrm{C}$. Unfortunately, the variation in water temperature confounded our results somewhat, as it was correlated with the treatments that we applied. Crab feeding rates are affected by ambient water temperatures, and the water was warmer during the high density trials. The small size of the experimental containers was an additional concern, since it effectively eliminated the search time of the predatory crabs. Thus, these experiments represented idealized foraging conditions and elucidated satiation levels of $H$. sanguineus rather than the actual functional response of the species.

Field caging experiments. To assess the influence of Hemigrapsus sanguineus and Carcinus maenas on juvenile mussels under more realistic circumstances, we deployed experimental cages at Millstone Point on 4 separate occasions. Special care was taken to reduce potential artifacts that often accompany caging experiments. For example, densities and sizes of the predators and prey used were based on population surveys at the site, there were alternative food resources available to predators, prey had appropriate habitat in which to hide, and natural diurnal/tidal stimuli were operative.

Mytilus edulis, 5 to $10 \mathrm{~mm} \mathrm{SL}$, were collected from rocky intertidal habitats and held in un-filtered seawater at the laboratory. One litre containers were used to hold mussels and each container had $50 \mathrm{M}$. edulis individuals in addition to several small rocks (longest axis was $\sim 3$ to $7 \mathrm{~cm}$ ). Over the course of 1 to $2 \mathrm{~d}$, most mussels attached themselves to rocks using their byssal threads. Mussels handled in this manner were used in the field caging experiments.

Plastic tubs $(40 \times 25 \times 15 \mathrm{~cm}$ deep $)$ with tightly-fitting mesh tops ( $8 \mathrm{~mm}$ mesh vexar screen) were used to create field cages. At the field site $(+40 \mathrm{~cm} \mathrm{MLW),} \mathrm{cobbles}$ were moved aside, holes were dug in the sediment, and cages were installed so that their tops were approximately flush with the sediment surface. Cages were placed $\sim 3 \mathrm{~m}$ apart and treatment positions (10 replicates of each) were randomly interspersed. The level of habitat structural complexity present at the site was mimicked inside the cages by placing rocks and cobbles atop a layer of sand. A natural assemblage of resident organisms was associated with the stones introduced to cages, therefore several food types were available to caged crabs.

A set of 50 mussels (now attached to rocks) was introduced to each field-deployed cage at the beginning of each experiment. The use of 50 mussels, 5 to $10 \mathrm{~mm} \mathrm{SL}$, in all experimental cages was appropriate given the sizes and densities of blue mussels in natural populations at the field site (see 'Results'). However, densities used in field experiments were much lower than those used in laboratory trials (50 mussels per field cage $\approx 5$ mussels per laboratory container).

Three separate field experiments were performed over a 2 yr period. In the first experiment (July 15 to 17 , 1998), 3 treatments were applied: exclusion cages (which excluded all crabs $>10 \mathrm{~mm} \mathrm{CW}$ ), Hemigrapsus inclusion cages (which included 1 male $H$. sanguineus, 25 to $30 \mathrm{~mm} \mathrm{CW}$ ), and partially opened cages (crabs of all sizes could freely enter and exit these cages). A second experiment was performed almost exactly 1 yr later (July 12 to 14, 1999). In addition to the treatments used previously, a fourth treatment was added to the second experiment (Carcinus inclusion cages, which included one $C$. maenas male 25 to $33 \mathrm{~mm} \mathrm{CW}$ cage $^{-1}$ ). Four treatments were again used for the final experiment (August 9 to 11, 1999). In this experiment, however, greater densities of smaller crabs were used in the Hemigrapsus and Carcinus inclusion treatments (i.e. 2 males and 2 females 14 to $25 \mathrm{~mm} \mathrm{CW}$ were used, rather than single large males).

After $2 \mathrm{~d}$, contents of the plastic tubs were sieved on a $2.0 \mathrm{~mm}$ mesh screen and intact mussels were censused to estimate mussel survivorship in each treat- 
ment of each experiment. When an empty, open mussel shell was observed with no chips or cracks (usually $<5 \%$ of the mussels), this loss was not considered a result of predation. Similarly, when mussels were found cracked but not consumed $(<5 \%$ of the mussels), the damage likely occurred during transport/ processing (i.e. it was not interpreted as a result of crab inclusion).

The 3 caging experiments were analyzed using 1way ANOVAs (with Scheffé post hoc tests). Assumptions of ANOVA were satisfied in each case after transforming the response variable $(\arcsin \sqrt{x / 100}$, where $x$ was the percent of Mytilus edulis remaining after $2 \mathrm{~d}$, Underwood 1997). Some replicates were eliminated from the analysis because cages were overturned by

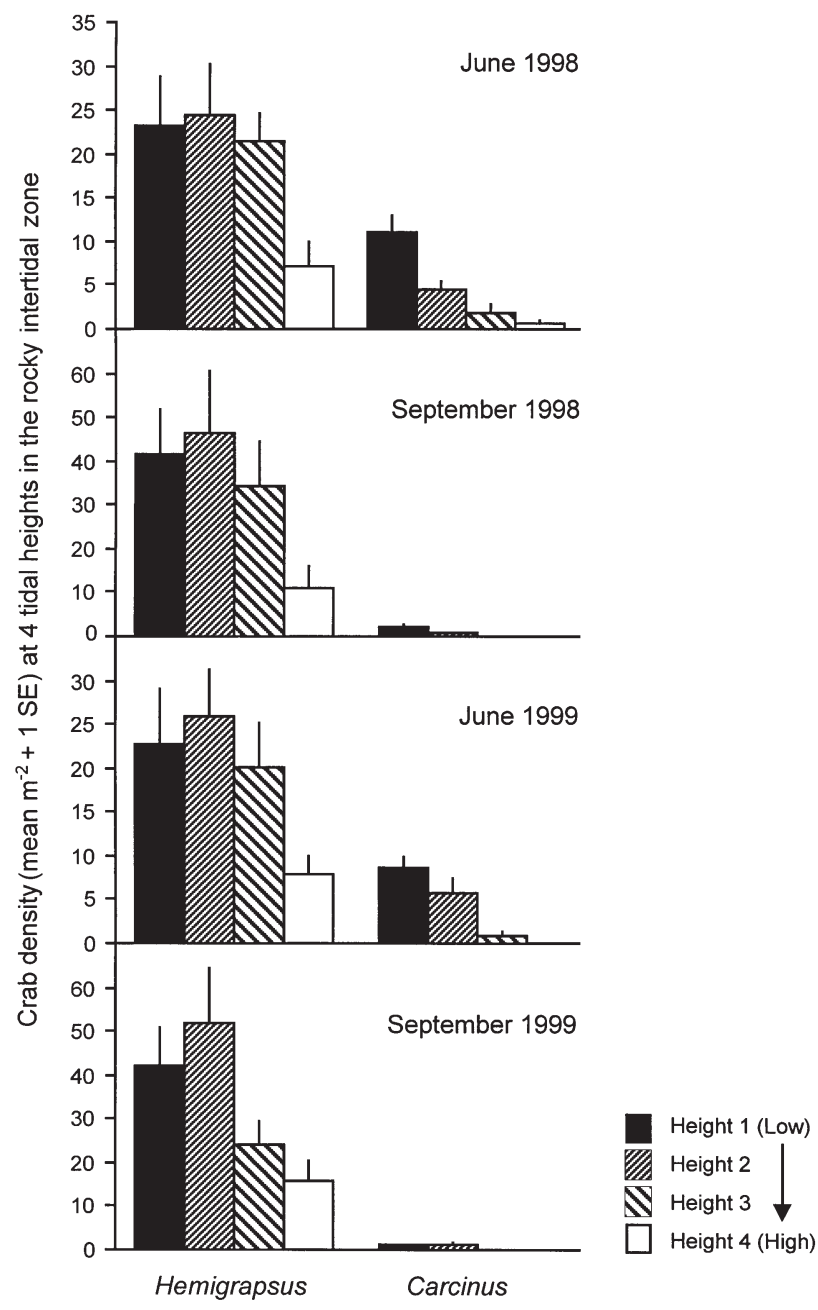

Fig. 1. Hemigrapsus sanguineus and Carcinus maenas. Vertical distribution of crabs inhabiting the rocky intertidal zone at Millstone Point, $\mathrm{CT}$, during the study period. Mean densities ( $\pm 1 \mathrm{SE}, \mathrm{n}=5$ ) of $H$. sanguineus and $C$. maenas are presented at 4 distinct tidal heights. Height 1 is centered at $\sim+10 \mathrm{~cm}$ MLW, Height $2 \sim+30$ MLW, Height $3 \sim+60$ MLW, and Height $4 \sim+80 \mathrm{~cm}$ MLW wave action; others were removed because crabs had died or molted (crab feeding generally ceases when crabs molt). However, at least 7 replicates were used for each treatment in each experiment and, in most cases, data from all 10 replicates treatment ${ }^{-1}$ were analyzed.

The loss of mussels from open cages was probably the result of both predation and emigration (either active or passive). Therefore, to understand the relative contributions of predation versus emigration, a separate cage-control experiment was performed in late July 1999. Six cages (with partially opened mesh tops) including 50 juvenile mussels were deployed at Millstone Point. Open cages should be accessible to any crabs present in the surrounding habitat. Here, however, crabs $>10 \mathrm{~mm} \mathrm{CW}$ were prevented from entering by a separate set of cages: $60 \mathrm{~cm} \times 60 \mathrm{~cm}$ cylindrical frames which were fully covered with $8 \mathrm{~mm}$ mesh vexar screen. One outer cage was used to enclose each of the partially opened cages $(n=6)$. The outer cages (volume $\approx 170000 \mathrm{~cm}^{3}$ ) were much larger than the enclosed open cages (volume $=15000 \mathrm{~cm}^{3}$ ). Consequently, the outer cages surrounded the holes where the open cages were deployed and extended to $40 \mathrm{~cm}$ above the sediment surface. Any large crabs in the area of the outer cage were removed prior to initiation of the experiment. After $2 \mathrm{~d}$, the contents of the open cages were sieved on a $2 \mathrm{~mm}$ mesh screen and the number of mussels remaining in each open cage was quantified. Thus, mussel losses from emigration (or passive wash-out by waves) were quantified in the absence of predation. While the outer cages may have reduced water flow across the open cages, the effects of wave energy were certainly greater than those of predators.

\section{RESULTS}

\section{Field surveys}

At Millstone Point, during the summers of 1998 and 1999, densities of Hemigrapsus sanguineus were much greater than those of Carcinus maenas (paired sign tests; $\mathrm{p}<0.0001$ at each date). For example, throughout the middle and lower intertidal zone, densities of $H$. sanguineus generally averaged $>20$ crabs $\mathrm{m}^{-2}$ whereas densities of $C$. maenas were usually $<10$ crabs $\mathrm{m}^{-2}$ (Fig. 1). While $H$. sanguineus was abundant and conspicuous throughout the summer in both years (densities of 40 to $90 \mathrm{crabs} \mathrm{m}^{-2}$ were common), H. sanguineus densities were generally greater in the late summer surveys (Table 1). This contrasted with green crabs, which were less abundant in September than in June ( $t$-tests, $\mathrm{p} \leq 0.0019$, both years). 
The average size of green crabs found at Millstone Point was $<20 \mathrm{~mm}$ CW during early summer. While Carcinus maenas can attain a maximum size of $85 \mathrm{~mm} \mathrm{CW}$ (Carlisle 1957), 99\% of the $C$. maenas sampled during this investigation were $<35 \mathrm{~mm} \mathrm{CW}$ (e.g. Fig. 2). Small individuals were predominant in populations of $H$. sanguineus as well. For example, the average size of $H$. sanguineus was $\sim 12 \mathrm{~mm} \mathrm{CW}$ in all 4 surveys. Crabs $>30 \mathrm{~mm} \mathrm{CW}$ were not observed during this study, even though $H$. sanguineus can reach sizes of 40 to $43 \mathrm{~mm} \mathrm{CW}$ (Fukui 1988, McDermott 1998 b pers. obs.).

While never observed in quadrats at low tide, large Carcinus maenas (i.e. green crabs >45 mm CW) were captured in crab traps at high tide. However, the number of crabs captured in traps was small (4.0 ind. $\operatorname{trap}^{-1} \pm 1.0$, all sizes combined, mean $\pm 1 \mathrm{SE}, \mathrm{n}_{\text {traps }}=4$ ).

The density of Mytilus edulis was $52.1 \pm 16.7$ ind. quadrat $^{-1}$ in 1998 (mean $\pm 1 \mathrm{SE}, \mathrm{n}=18$ ) and was 13.0 \pm 3.6 ind. quadrat ${ }^{-1}$ in 1999 (mean $\pm 1 \mathrm{SE}, \mathrm{n}=18$ ). This represented a significant, 4 -fold decrease in the

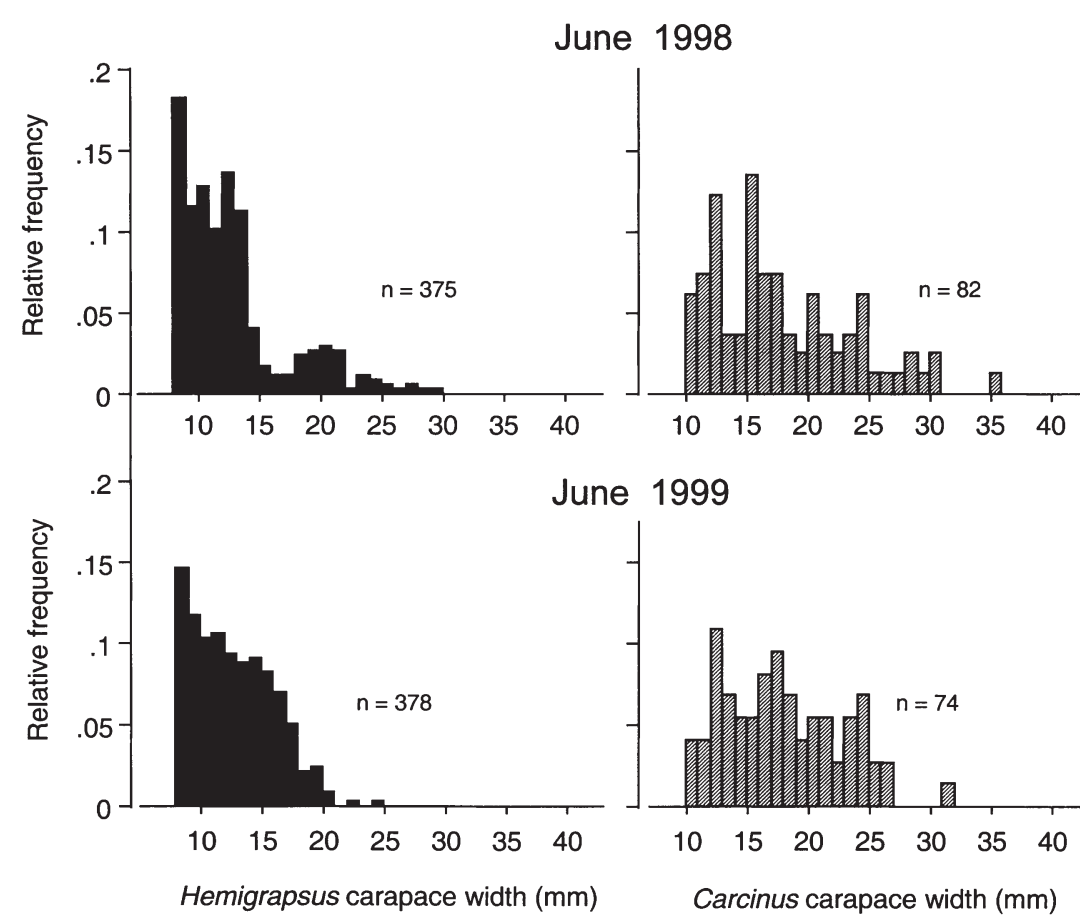

Fig. 2. Size distributions of Hemigrapsus sanguineus and Carcinus maenas sampled from Millstone Point, CT, in June 1998 and June 1999. Size distributions are not presented for the September data sets because $C$. maenas densities were extremely low ( $<15$ in both cases) total density of blue mussels between years ( $t$-test, $\mathrm{p}=0.0014)$. While the decline in small blue mussels was dramatic (e.g. density of the 0 to $10 \mathrm{~mm}$ SL sizeclass was 5-fold lower in 1999, p < 0.0001), the density of mussels $>30 \mathrm{~mm}$ SL did not differ significantly between years $(0.15 \leq \mathrm{p} \leq 0.81)$ (Fig. 3).

\section{Laboratory feeding experiments}

Hemigrapsus sanguineus consumed small Mytilus edulis in great numbers. While there was considerable variation, individual H. sanguineus apparently did not satiate until high densities of prey were offered (Fig. 4). The level of satiation was estimated at 100 to 150 juvenile mussels predator ${ }^{-1} \mathrm{~d}^{-1}$ (based on a relationship between the number of $M$. edulis available $(y)$ and the number of $M$. edulis consumed $(x)$; $\mathrm{p}<$ $0.0001, r^{2}=0.786 ; \log (y)=0.478+$ $\left.0.018 x+0.00005 x^{2}\right)$. Of the $18 H$. sanguineus that were given 100 or more M. edulis individuals, 10 crabs (56\%) consumed $100+$ mussels $\mathrm{d}^{-1}$. In all except the highest prey density treatment, at least 1 crab consumed every mussel it was given. The maximum number consumed by a single crab was 215 juvenile mussels $\mathrm{d}^{-1}$. 

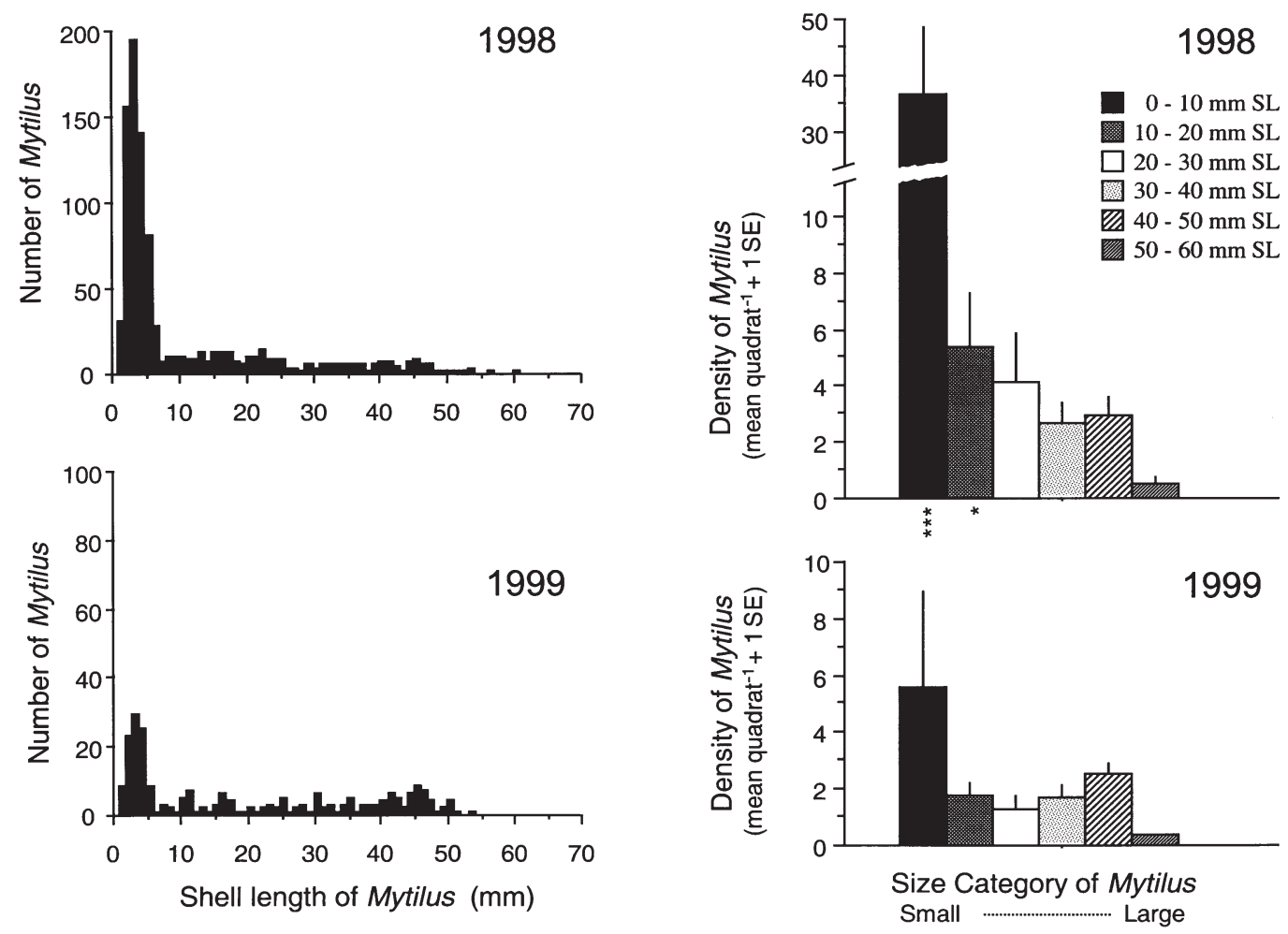

Fig. 3. Mytilus edulis at Millstone Point (July 1998 and July 1999): size distributions are presented on the left. Blue mussels were divided into $10 \mathrm{~mm}$ SL size classes. Mean densities $\operatorname{class}^{-1}$ quadrat ${ }^{-1}\left(+1 \mathrm{SE}, \mathrm{n}_{\text {quadrats }}=18\right.$ ) are presented on the right. Densities of each size class were compared between years with Mann-Whitney $U$-tests. Asterisks denote density differences between

years; $p=0.0246 .{ }^{*}$ represents a marginally significant result because a Bonferroni correction was used $(\alpha=0.0167)$

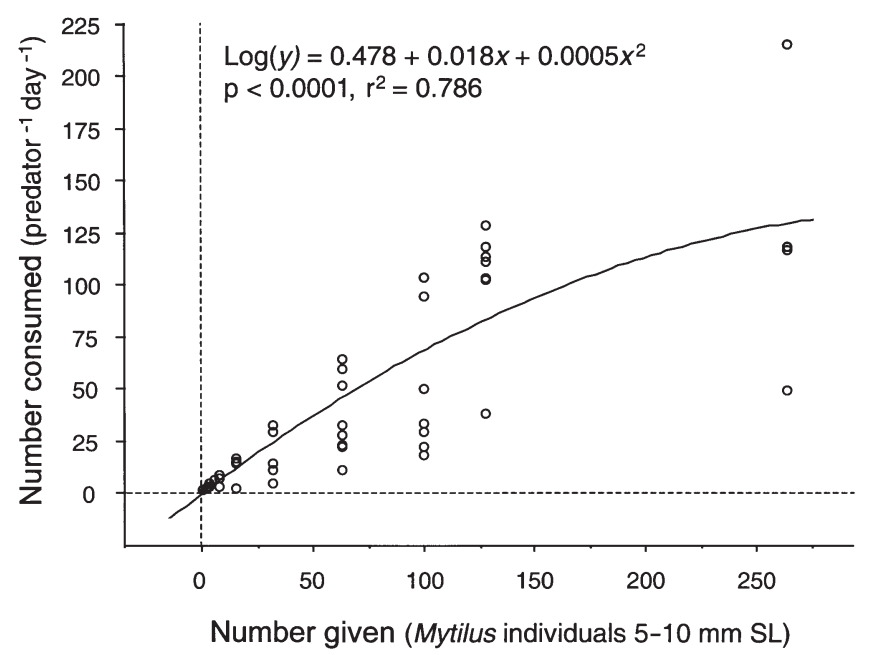

Fig. 4. Consumpotion of Mytilus edulis by Hemigrapsus sanguineus in the laboratory. Each data point represents the consumption of $M$. edulis by an individual crab (a male $H$. sanguineus 25 to $30 \mathrm{~mm} \mathrm{CW}$ ) during a $24 \mathrm{~h}$ trial. Shells that were cracked but not consumed were not counted as predation. Neither were open shells with no visible chips or cracks. The curve through these data is a visual aid only; the equation and regression statistics are based on log-transformed data. With no transformation, assumptions of regression were vio-

lated due to increased variance at high prey densities

\section{Field caging experiments}

Most (92 to $96 \%$ ) of the 50 experimental mussels were recovered from exclusion cages after $2 \mathrm{~d}$. However, when crabs had access to the cages, fewer juvenile blue mussels were recovered (Fig. 5). In all 3 experiments, the density of juvenile blue mussels was significantly lower in Hemigrapsus inclusion cages than it was in exclusion cages (Scheffé post-hoc tests, $p \leq 0.0059$ in all cases). The density of juvenile blue mussels was reduced by small $H$. sanguineus (crabs 14 to $23 \mathrm{~mm} \mathrm{CW}$ ) as well as by large $H$. sanguineus (i.e. males 25 to $30 \mathrm{~mm} \mathrm{CW}$ ).

Similarly, all sizes of Carcinus maenas used in the experiments reduced the density of juvenile blue mussels (Fig. 5). On a per capita basis, however, C. maenas had a greater impact on juvenile mussels than Hemigrapsus sanguineus. For example, $<10 \%$ of the mussels remained in Carcinus inclusion cages after $2 \mathrm{~d}$, whereas 40 to $50 \%$ remained in Hemigrapsus inclusion cages after $2 \mathrm{~d}$.

Results from the open cage treatments were similar in all 3 experiments: few of the experimental mussels were recovered from open cages after $2 \mathrm{~d}$ (Fig. 5). The results differed, however, when predators were pre- 


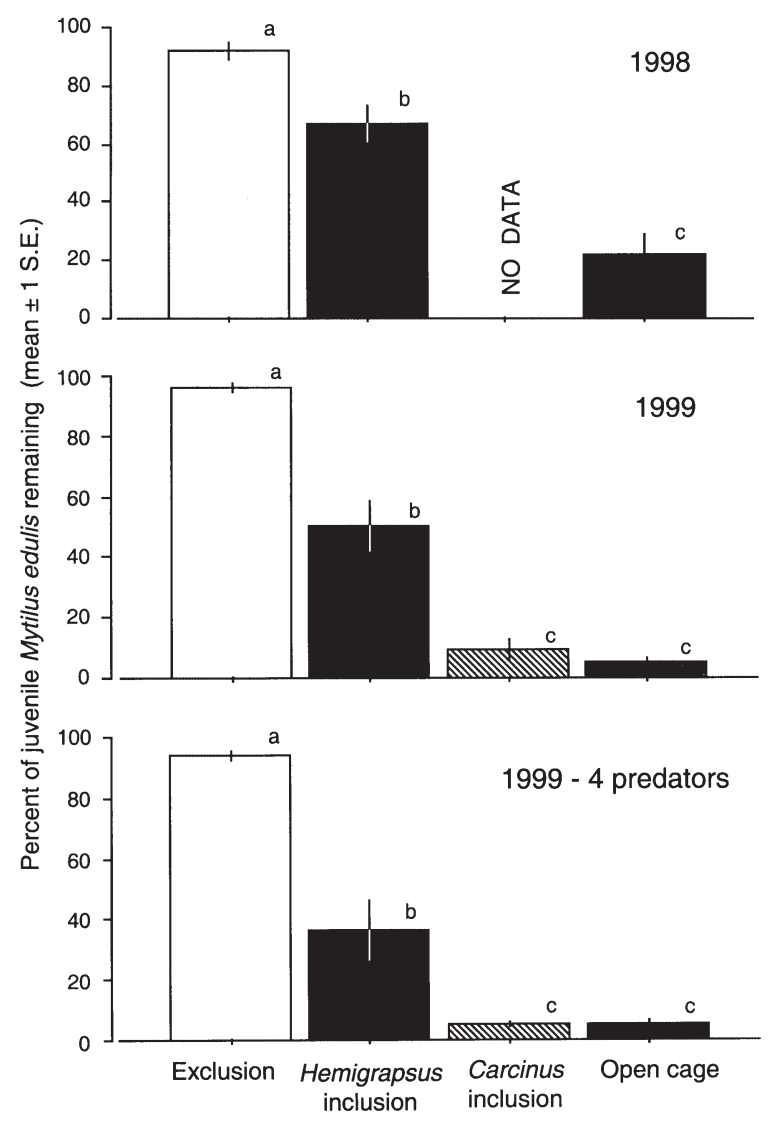

Fig. 5. Mytilus edulis. Results of 3 experiments conducted at Millstone Point, CT. The number of replicates treatment ${ }^{-1}$ date $^{-1}$ was between 7 and 10 (see 'Methods'). The percentage of $M$. edulis remaining in cages after $2 \mathrm{~d}$ (i.e. the dependent variable, mean $\pm 1 \mathrm{SE}$ ) differed with respect to treatment (ANOVA on $\arcsin \left(\right.$ data) ${ }^{0.5}, \mathrm{p}<0.0001$ in all 3 cases). Fifty mussels were introduced to every cage at the beginning of each experiment. Letters $(a, b, c)$ indicate statistical significance using Scheffé post-hoc tests; means with the same letter are not significantly different from each other at $\alpha=0.05$

vented from entering the open cages. In the cage-control experiment (when the partially opened cages were covered over by large, outer cages), nearly all of the 50 juvenile blue mussels were recovered after $2 \mathrm{~d}(48.3 \pm$ 0.6 mussels cage ${ }^{-1}$, mean $\pm 1 \mathrm{SE}, \mathrm{n}=6$ ). Finally, the presence (and relative amounts) of shellhash in the different treatments of each experiment indicated that predation by crabs was primarily responsible for the disappearance of mussels from the cages.

\section{DISCUSSION}

The small size of Hemigrapsus sanguineus belies its potential for causing ecological and economic harm. Approximately $10 \mathrm{yr}$ following its invasion of Long Island Sound, its impacts are becoming evident. $H$. sanguineus is apparently replacing Carcinus maenas in rocky intertidal habitats of southern New England, and the consequences of this exotic species replacement may be significant for the region's biota. Based on the results of this study and contrary to early predictions, the net effect of the Asian crab invasion is probably negative for some rocky intertidal inhabitants (i.e. the predation pressure exerted by crabs in rocky intertidal areas is greater at present than it was when $C$. maenas occupied these habitats in the absence of $H$. sanguineus). While green crabs are generally larger and more carnivorous than $H$. sanguineus (Carlisle 1957, Fukui 1988, Ropes 1989, Lohrer \& Whitlatch 1997, Lohrer et al. 2000), the Asian crabs may have greater population-level effects than green crabs because of their extremely high densities. Here, we measured the per capita impacts of both alien crab species on native blue mussels $M$. edulis and estimated their relative effects at the population level.

Overall densities of blue mussels differed in 1998 and 1999 at Millstone Point. The density of mussels in the 0 to $10 \mathrm{~mm}$ SL size class varied the most, declining by a factor of 5 between years. Year-to-year variation in recruitment success is probably the best explanation for the decline in Mytilus edulis populations, given the time-scale of this investigation. Nevertheless, the analyses revealed that small $M$. edulis apparently suffer high mortality relative to large $M$. edulis (Fig. 3). For example, most of the mussels $<10 \mathrm{~mm}$ SL present in 1998 did not survive until the following year (otherwise they would have been detected in 1999 in the 10 to $20 \mathrm{~mm}$ size range).

There are many conceivable explanations for the size-specific mortality of Mytilus edulis at Millstone Point, including predation by crabs. The Asian shore crab Hemigrapsus sanguineus is fairly small, extremely abundant, and consumes small blue mussels. In laboratory feeding trials, $H$. sanguineus satiated after consuming 100 to 150 juvenile blue mussels predator $^{-1} \mathrm{~d}^{-1}$ (Fig. 4). These high predation rates indicated a potential for $H$. sanguineus to influence natural populations of $M$. edulis in rocky intertidal habitats of southern New England. Results of field experiments conducted at Millstone Point supported this hypothesis.

In the 3 field experiments, fewer mussels survived in treatments that included Hemigrapsus sanguineus relative to treatments that excluded crabs (Fig. 5). These findings were consistent between years and when either large or small $H$. sanguineus were used. Similarly, Carcinus maenas $<40 \mathrm{~mm} \mathrm{CW}$ were effective predators on small Mytilus edulis during this investigation (as was expected from previous work that examined C. maenas $>60 \mathrm{~mm} \mathrm{CW}$ and mussels 40 to $60 \mathrm{~mm} \mathrm{SL}$; Elner \& Hughes 1978). On a per capita 
basis, C. maenas consumed more juvenile blue mussels than $H$. sanguineus of similar size (e.g. C. maenas reduced the density of $M$. edulis by 90 to $95 \%$ during the experiments in 1999, whereas $H$. sanguineus reduced the density of $M$. edulis by 50 to $60 \%$ during the same experiments) (Fig. 5).

Mussel loss from open cages probably included both predatory and non-predatory components; during the 3 main experiments, it was not possible to distinguish mussels that emigrated from the treatment (i.e. were washed out of cages by waves) from those that were consumed by predators. Based on the results of a separate cage-control experiment, however, non-predatory losses were probably minimal. When predators $>10 \mathrm{~mm}$ were excluded from open cages, there was almost no emigration/wash-out (i.e. $96.7 \% \pm 1.2$ of the mussels were recovered after $2 \mathrm{~d}$; mean $\pm 1 \mathrm{SE}$ ). Furthermore, the quantities of shell hash in the open treatments indicated that crabs were preying on juvenile mussels (especially when compared to the small amounts of shell hash in exclusion treatments and in the cage control experiment treatments).

Background levels of predation (estimated from open cages) were very high at Millstone Point during 1998 and 1999 (Fig. 5). Most likely, Hemigrapsus sanguineus was responsible for most of the loss of blue mussels from open cages during these experiments, and there was ample evidence to support this premise. While Carcinus maenas was a more effective predator than $H$. sanguineus on an individual basis, H. sanguineus was much more abundant than $C$. maenas (especially at $+40 \mathrm{~cm} \mathrm{MLW}$, the tidal height at which the cages were deployed; Fig. 1, Table 1). Therefore, from a population standpoint, $H$. sanguineus was the numerically dominant predator at the time the experiments were conducted. Large C. maenas undergoing tidal migrations (i.e. only present in intertidal areas during high tides; Naylor 1958) were probably not sampled effectively during low tide surveys, so it is possible that their effects were underestimated. However, all of the C. maenas found in the open cages at the end of the experiments were small (averaging 17 to $23 \mathrm{~mm} \mathrm{CW}$ ). Furthermore, when crab traps were baited with cracked $M$. edulis and deployed at Millstone Point for 2 complete tidal cycles, few large adult C. maenas were caught.

In the 4-predator experiment (August 9 to 11, 1999), Carcinus maenas consumed an average of 5.6 mussels predator $^{-1}$ cage $^{-1} \mathrm{~d}^{-1}$, while Hemigrapsus sanguineus consumed an average of 3.6 mussels predator ${ }^{-1}$ cage $^{-1}$ $\mathrm{d}^{-1}$. Therefore, in order to exert a comparable effect on M. edulis populations in the rocky intertidal zone, densities of $H$. sanguineus had to be 1.6 times greater than densities of C. maenas. In 1998-1999, densities of $H$. sanguineus were 4 to 60 times greater than densities of C. maenas. Thus, during the study period, $H$. sanguineus likely had a greater impact on juvenile $M$. edulis than C. maenas.

Assuming that average densities of Carcinus maenas were 20 to 40 crabs $\mathrm{m}^{-2}$ prior to the arrival of Hemigrapsus sanguineus (Crothers 1970, Fogarty 1976, Klein-Breteler 1976, Dean 1979, Berrill 1982, Mansour 1983, Ropes 1989, Lohrer \& Whitlatch 1997), densities of $H$. sanguineus must average 32 to $64 \mathrm{crabs} \mathrm{m}^{-2}$ in order for it to exert a comparable impact. Average densities of $H$. sanguineus were within this range during both years of the study. More than 50 crabs $\mathrm{m}^{-2}$ were present in the mid- to lower intertidal at Millstone Point (Fig. 1) and maximum density was $98 \mathrm{crabs} \mathrm{m}^{-2}$. Furthermore, average densities of $H$. sanguineus now exceed 70 crabs $\mathrm{m}^{-2}$ at sites to the east and west of Millstone Point (Lohrer 2000) and maximum densities

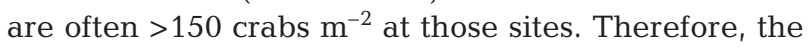
replacement of $C$. maenas by $H$. sanguineus in rocky intertidal habitats of southern New England is apparently a net negative influence on populations of $M$. edulis in these areas. However, extrapolation of these results to other (e.g. subtidal) habitats is not yet warranted.

While many view the invasion of Carcinus maenas as a significant event in the natural history of New England (Vermeij 1982a,b, Leonard et al. 1999), the invasion of Hemigrapsus sanguineus may also become an influential structuring force in rocky intertidal communities of the region. Although $H$. sanguineus is a relatively small crab, its high densities and omnivorous feeding habits make it a significant risk to small benthic organisms. The presence (and abundance) of $H$. sanguineus in rocky intertidal habitats may have reduced the value of this habitat type as a refuge from predation. Thus, the biological composition of $\mathrm{New}$ England's rocky shoreline could be altered by this invader as it continues to spread along the northeast coast of North America.

Acknowledgements. Our work on aquatic nuisance species was made possible by the Connecticut Sea Grant College Program, which provided financial and moral support to A.M.L. from 1996 to 2000. The American Museum of Natural History Lerner-Gray Fund for Marine Research, the QLF Atlantic Center for the Environment-Sounds Conservancy Grants Program, and the Francis R. Trainor Foundation at the University of Connecticut also deserve recognition for their support of A.M.L. Finally, many thanks to those who helped with field work; without the graduate students, technicians, and others associated with UConn, a project of this scale could not have been completed. Permission to use the Millstone Point sampling site was granted by the Northeast Utilities Environmental Laboratory, and we thank Jim Foertch for his assistance. J. Carlton, R. Colwell, A. Hines, E. Schultz, J. Kremer, R. Kneib, and 3 anonymous reviewers read earlier versions of this manuscript and all helped to improve it. 


\section{LITERATURE CITED}

Berger MS (1998) Predator-prey relations between the green crab, Carcinus maenas and three small gastropods, Mitrella lunata, Anachis lafresnayi and Anachis avara. Honor's thesis, Department of Marine Sciences, University of Connecticut, Groton

Berman JL, Harris L, Lambert W, Buttrick M, Dufresne M (1992) Recent invasions of the Gulf of Maine: three contrasting ecological histories. Conserv Biol 6:435-441

Berrill M (1982) The life cycle of the green crab Carcinus maenas at the northern end of its range. J Crustac Biol 2: 31-39

Carlisle DB (1957) On the hormonal inhibition of moulting in Decapod Crustacea: II. The terminal anecdysis in crabs. J Mar Biol Assoc UK 36:291-307

Carlton JT (1989) Man's role in changing the face of the ocean: biological invasions and implications for conservation of near-shore environments. Conserv Biol 3:265-273

Carlton JT (1993) A steady stream of invading organisms creates ecological roulette in New England waters. Estuar Res Fed News 19:11

Carlton JT, Geller JB (1993) Ecological roulette: the global transport of nonindigenous marine organisms. Science 261:78-82

Cohen AN, Carlton JT (1998) Accelerating invasion rate in a highly invaded estuary. Science 279:555-558

Crothers JH (1970) The distribution of crabs on rocky shores around the Dale Peninsula. Field Stud 3:263-274

Davies G (1966) Shore crabs, Carcinus maenas, and mussel culture. Rep Challenger Soc 3:31

Dean D (1979) Impacts of thermal addition and predation on intertidal populations of the blue mussel, Mytilus edulis L. Proc Natl Shellfish Assoc 69:49-53

Ebling FJ, Kitching JA, Muntz L, Taylor CM (1964) The ecology of Lough Ine XIII. Experimental observations of the destruction of Mytilus edulis and Nucella lapillus by crabs. J Anim Ecol 33:73-82

Elner RW (1981) Diet of green crab Carcinus maenas (L.) from Port Hebert, southwestern Nova Scotia. J Shellfish Res 1: 89-94

Elner RW, Hughes RN (1978) Energy maximization in the diet of the shore crab, Carcinus maenas. J Anim Ecol 47: 103-116

Fogarty MJ (1976) Competition and resource partitioning in 2 species of Cancer (Crustacea, Brachyura). Masters thesis, Department of Zoology, University of Rhode Island, Kingston

Fukui Y (1988) Comparative studies on the life history of the grapsid crabs (Crustacea, Brachyura) inhabiting intertidal cobble and boulder shores. Publ Seto Mar Biol Lab 33: $121-162$

Glude JB (1955) The effects of temperature and predators on the abundance of the soft-shell clam, Mya arenaria, in New England. Trans Am Fish Soc 84:13-26

Grosholz ED, Ruiz GM (1995) Spread and potential impact of the recently introduced European green crab, Carcinus maenas, in central California. Mar Biol 122:239-247

Juanes F (1992) Why do decapod crustaceans prefer smallsized molluscan prey? Mar Ecol Prog Ser 87:239-249

Kitching JA, Sloane JF, Ebling FJ (1959) The ecology of Lough Ine. VIII. Mussels and their predators. J Anim Ecol 28:331-341

Klein-Breteler WCM (1976) Settlement, growth, and production of the shore crab, Carcinus maenas, on tidal flats in the Dutch Wadden Sea. Neth J Sea Res 10:354-376

Leonard GH, Bertness MD, Yund PO (1999) Crab predation, waterborne cues, and inducible defenses in the blue mussel, Mytilus edulis. Ecology 80:1-14

Lohrer AM (2000) Mechanisms and consequences of an exotic crab species invasion. PhD thesis, Department of Ecology and Evolutionary Biology, University of Connecticut, Storrs

Lohrer AM, Whitlatch RB (1997) Ecological studies on the recently introduced Japanese shore crab (Hemigrapsus sanguineus), in eastern Long Island Sound. In: Balcom NC (ed) Proceedings of the Second Northeast Conference on Nonindigenous Aquatic Nuisance Species. Connecticut Sea Grant College Program, University of Connecticut, Groton, p 49-60

Lohrer AM, Whitlatch RB, Wada K, Fukui Y (2000) Home and away: comparisons of resource utilization by a marine species in native and invaded habitats. Biol Invasions 2(1): 41-57

Mansour RA (1983) Habitat selection and agonistic behavior of 2 sympatric species of crabs, Cancer irroratus and Carcinus maenas. Masters thesis, Department of Zoology, University of Rhode Island, Kingston

McDermott JJ (1998a) The western Pacific brachyuran (Hemigrapsus sanguineus: Grapsidae) in its new habitat along the Atlantic coast of the United States: geographic distribution and ecology. ICES J Mar Sci 55:289-298

McDermott JJ (1998b) The western Pacific brachyuran Hemigrapsus sanguineus (Grapsidae) in its new habitat along the Atlantic coast of the United ied States: feeding, cheliped morphology and growth. In: Schram FR, von Vaupel Klein JC (eds) Crustaceans and the biodiversity crisis. Brill, Leiden, p 425-444

Naylor E (1958) Tidal and diurnal rhythms of locomotory activity in Carcinus maenas (L.). J Exp Mar Biol Ecol 35: $602-610$

Osman RW, Whitlatch RB (1995a) Ecological factors controlling the successful invasion of three species of ascidians into marine subtidal habitats of New England. In: Balcom NC (ed) Proceedings of the Northeast Conference on Nonindigenous Aquatic Nuisance Species. Connecticut Sea Grant College Program, University of Connecticut, Groton, p 49-60

Osman RW, Whitlatch RB (1995b) The influence of resident adults on settlement: experiments with four species of ascidians. J Exp Mar Biol Ecol 190:199-220

Paine RT (1976) Size-limited predation: an observational and experimental approach with the Mytilus-Pisaster interaction. Ecology 57:858-873

Peterson CH (1991) Intertidal zonation of marine invertebrates in sand and mud. Am Sci 79:236-249

Reise K (1985) Tidal flat ecology. Springer-Verlag, Berlin

Ropes JW (1968) The feeding habits of the green crab, Carcinus maenas (L). US Fish Wild Serv Fish Bull 67:183-203

Ropes JW (1989) The food habits of five crab species at Pettaquamscutt River, Rhode Island. US Fish Wild Serv Fish Bull 87:197-204

Stachowicz JJ, Whitlatch RB, Osman RW (1999) Species diversity and invasion success in a marine ecosystem. Science 286:1577-1579

Underwood AJ (1997) Experiments in ecology: their logical design and interpretation using analysis of variance. Cambridge University Press, Cambridge, MA

Underwood AJ, Denley EJ (1984) Paradigms, explanations, and generalizations in models for the structure of intertidal communities on rocky shores. In: Strong D, Simberloff D, Abele LG, Thistle AB (eds) Ecological communities: conceptual issues and the evidence. Princeton University Press, Princeton, p 151-180 
Vermeij GJ (1982a) Phenotypic evolution in a poorly dispersing snail after the arrival of a predator. Nature 299:349-350 Vermeij GJ (1982b) Environmental change and the evolutionary history of the periwinkle (Littorina littorea) in North America. Evolution 36:561-580

Whitlatch RB, Osman RW, Frese A, Malatesta R, Mitchel P, Sedgwick L (1995) The ecology of two introduced marine ascidians and their effects on epifaunal organisms in Long

Editorial responsibility: Ronald Kneib (Contributing Editor), Sapelo Island, Georgia, USA
Island Sound. In: Balcom N (ed) Proceedings of the Northwest Conference on Nonindigenous Aquatic Nuisance Species. Connecticut Sea Grant College Program, University of Connecticut, Groton, p 29-48

Williams AB, McDermott JJ (1990) An eastern United States record for the western Indo-Pacific crab, Hemigrapsus sanguineus (Crustacea: Decapoda: Grapsidae). Proc Biol Soc Wash 103(1):108-109

Submitted: November 26, 2000; Accepted: May 27, 2001 Proofs received from author(s): January 29, 2002 